\title{
A genetic approach to study the relationship between maternal Vitamin D status and newborn anthropometry measurements: the Vitamin D pregnant mother (VDPM) cohort study
}

\author{
Arif Sabta Aji ${ }^{1,2} \cdot$ Erwinda Erwinda $^{3} \cdot$ Rosfita Rasyid $^{3} \cdot$ Yusrawati Yusrawati $^{4}$. \\ Safarina G Malik ${ }^{5}$. Buthaina Alathari ${ }^{6}$. Julie Anne Lovegrove ${ }^{6}$. \\ Nur Indrawaty Lipoeto ${ }^{7} \cdot$ Karani Santhanakrishnan Vimaleswaran ${ }^{6}$
}

Received: 14 May 2019 / Accepted: 17 December 2019 / Published online: 27 January 2020

(C) The Author(s) 2020

\begin{abstract}
Purpose Adverse effects of maternal vitamin D deficiency have been linked to adverse pregnancy outcomes. We investigated the relationship between maternal vitamin D status and newborn anthropometry measurements using a genetic approach and examined the interaction between genetic variations in involved in vitamin D synthesis and metabolism and maternal vitamin D concentrations on newborn anthropometry.

Methods The study was conducted in 183 pregnant Indonesian Minangkabau women. Genetic risk scores (GRSs) were created using six vitamin D-related single nucleotide polymorphisms and their association with 25-hydroxyvitamin D [25(OH)D] levels and newborn anthropometry (183 infants) were investigated.

Results There was no significant association between maternal 25(OH)D concentrations and newborn anthropometry measurements ( $P>0.05$, for all comparisons). After correction for multiple testing using Bonferroni correction, GRS was significantly associated with $25(\mathrm{OH}) \mathrm{D}$ in the third trimester $(P=0.004)$. There was no association between GRS and newborn anthropometric measurements; however, there was an interaction between GRS and $25(\mathrm{OH}) \mathrm{D}$ on head circumference $(P=0.030)$, where mothers of neonates with head circumference $<35 \mathrm{~cm}$ had significantly lower $25(\mathrm{OH}) \mathrm{D}$ if they carried $\geq 4$ risk alleles compared to those who carried $\leq 3$ risk alleles.

Conclusion Our findings demonstrate the impact of vitamin D-related GRS on 25(OH)D and provides evidence for the effect of vitamin D-related GRS on newborn anthropometry through the influence of serum 25(OH)D levels among Indonesian pregnant women. Even though our study is a prospective cohort, before the implementation of vitamin D supplementation programs in Indonesia to prevent adverse pregnancy outcomes, further large studies are required to confirm our findings.
\end{abstract}

Keywords Vitamin D $\cdot$ Single nucleotide polymorphisms $\cdot 25$-hydroxyvitamin D $\cdot$ Pregnancy $\cdot$ Newborn anthropometry $\cdot$ Genetic risk score, West Sumatra

Electronic supplementary material The online version of this article (https://doi.org/10.1007/s40200-019-00480-5) contains supplementary material, which is available to authorized users.

Karani Santhanakrishnan Vimaleswaran

v.karani@ reading.ac.uk

Arif Sabta Aji

sabtaaji@gmail.com

Erwinda Erwinda

safirawinda7@gmail.com

Rosfita Rasyid

rosfitarasyid135ros@gmail.com

Yusrawati Yusrawati

yusrawati65@med.unand.ac.id

\author{
Safarina G Malik \\ ina@eijkman.go.id \\ Buthaina Alathari \\ b.e.a.a.alathari@pgr.reading.ac.uk \\ Julie Anne Lovegrove \\ j.a.lovegrove@ reading.ac.uk \\ Nur Indrawaty Lipoeto \\ indralipoeto@med.unand.ac.id
}

Extended author information available on the last page of the article 


\section{Introduction}

As one of the tropical countries in Southeast Asia located at the equator, Indonesia has an abundant sunlight all year round. According to recent studies, vitamin D deficiency in Indonesian women ranges between 60 and 95\% [1-5]. Adequacy of maternal vitamin D status is important for the development of bone, teeth, immune system and general growth of the foetus [5]. Vitamin D insufficiency during pregnancy have been shown to be associated with adverse pregnancy outcomes such as small-for-gestational-age (SGA), neurodevelopment and cognitive impairment, high blood pressure in women and infants, respiratory infections, increased incidence of infants treated in neonatal intensive care unit, and health outcomes in infants such as asthma, atopic allergy, and autoimmune disorders such as type 1 diabetes mellitus [6-11].

Hereditary factors have been shown to affect $29 \%$ to $80 \%$ of serum 25-hydroxyvitamin D [25(OH)D] concentrations [11]. Candidate gene studies have identified twelve genes based on the genome-wide association studies (GWAS) for 25(OH)D (GC, CYP24A1, CYP2R1, DHCR7) [12], GWAS for skin colour/tanning (interferon regulatory factor 4 (IRF4); melanocortin 1 receptor (MC1R); oculocutaneous albinism type 2 (OCA2); solute carrier family 45 , member 2 (SLC45A2); tyrosinase (oculocutaneous) (TYR)) [13-15], and candidate gene studies for vitamin D pathway genes (VDR, cytochrome $\mathrm{P} 450$, family 27 , subfamily A, polypeptide 1 (CYP27A1); cytochrome P450, family 27, subfamily B, polypeptide 1 (CYP27B1)) [16]. Recent GWASs have confirmed the association of six genetic variants in the following genes (short/branched chain acyl-CoA dehydrogenase (ACADSB), GC, DHCR7, CYP2R1, and CYP24A1) with $25 \mathrm{OHD}$ levels $[12,17]$, and these variants were found near genes involved in cholesterol synthesis, hydroxylation, and vitamin D transport that affects vitamin D status. The metabolic pathways and synthesis of vitamin $\mathrm{D}$ are regulated by the specific genes present in the pathway and the pathway is initiated by the exposure to UVB rays (vitamin $\mathrm{D}_{3}$ ) and dietary intake of vitamin D sources (vitamin $\mathrm{D}_{2}$ ).

Previous GWASs $[12,17]$ have identified common genetic variations that influence vitamin D status in western populations; however, very few studies have investigated the influence of common genetic variations on vitamin D status in populations within Southeast Asia, especially in Indonesian population. In this study, we explored the association between maternal vitamin $\mathrm{D}$ status and newborn anthropometry measurements using a genetic approach. Given the high level of confounding factors that exists between maternal vitamin D status and newborn anthropometry measurements, we used genetic variants as markers of maternal vitamin D status and tested for their association with newborn anthropometry measurements as genetic associations are less prone to confounding. In addition, we also investigated whether the association between genetic variants and newborn anthropometry measurements were modified by $25(\mathrm{OH}) \mathrm{D}$ concentrations in Indonesian pregnant women from West Sumatra.

\section{Methodology}

\section{Study population}

The study was conducted among singleton pregnant women of West Sumatran Vitamin D Pregnant Mother (VDPM) cohort study in West Sumatra, from July 2017 to April 2018. The study was performed at community health centres in five cities (Padang, Pariaman, Payakumbuh, Padang Pariaman, and Lima Puluh Kota) in West Sumatra, Indonesia. In this study, participants were followed up from the first trimester (T1) to third trimester (T3) of pregnancy and at delivery to determine newborn anthropometry measurements (birth weight, birth length and head circumference). This study was conducted in accordance with the declaration of Helsinki and approved by the Ethics Committees of Medical Faculty, Andalas University (No. 262/KEP/FK/2016). All women provided written informed consent prior to the start of the data collection.

All participants were pregnant women who were recruited during their first antenatal care checks at the public health centres. Inclusion criteria included: 1) pregnant women willing to visit public health care at each site, 2) those who were in the $\mathrm{T} 1(<13$ weeks) of their singleton pregnancy, 3) those who were healthy based on medical examination, and 4) those who were willing to participate by signing the informed consent and following the research procedures. Stratified random sampling was applied for the data collection that took place at two research locations: mountainous and coastal areas. Public health centers that had high numbers of the first-trimester pregnant mothers were chosen for the data collection. Women were excluded from the study if they had multiple pregnancies, some common complications of pregnancy such as preeclampsia, miscarriage or pregnancy loss, stillbirth, and they had chronic illness like diabetes, hypertension, cardiovascular disease, or hypothyroidism. Women who were taking drugs that can interfere with vitamin D metabolism such as antiepileptic agents, glucocorticoids, anti-oestrogens or antiretroviral drugs during pregnancy were excluded. Out of 239 women, 53 were dropped out for different reasons, including pregnancy loss, change of residence, not willing to continue research, and those who could not be contacted again. The number of pregnancy loss due to complications of pregnancy such as foetal inflammation, stillbirth, and abnormal foetal development was 25 (13.44\%). There were 
3 cases of preterm birth, 8 cases of stillbirth, and 14 cases of miscarriage. Finally, we obtained 186 pregnant women who completed all requirements and attended follow-ups from T1 to delivery. After excluding three samples due to low DNA yield, a total of 183 mother and infant pairs were used for the present study. Participant's recruitment process is shown in detail in Fig. 1.

\section{Study Participant's characteristics}

Maternal sociodemographic factors were assessed using a standardized questionnaire administered by trained field data collector (enumerator, i.e., a registered nutritionist).
The questionnaire included information on demographics, maternal occupation, education, and pregnancy profile. These data were prospectively collected from medical records or interviews. Maternal sociodemographic characteristics included age, education level (primary, secondary, and tertiary levels), maternal working status (working and not working), and geographical status (mountainous and coastal area). Maternal health status included prepregnancy BMI, and mid-upper arm circumference (MUAC). Maternal lifestyle included the outdoor activity to measure the sun exposure status during pregnancy and maternal vitamin $\mathrm{D}$ and calcium supplementation during pregnancy.

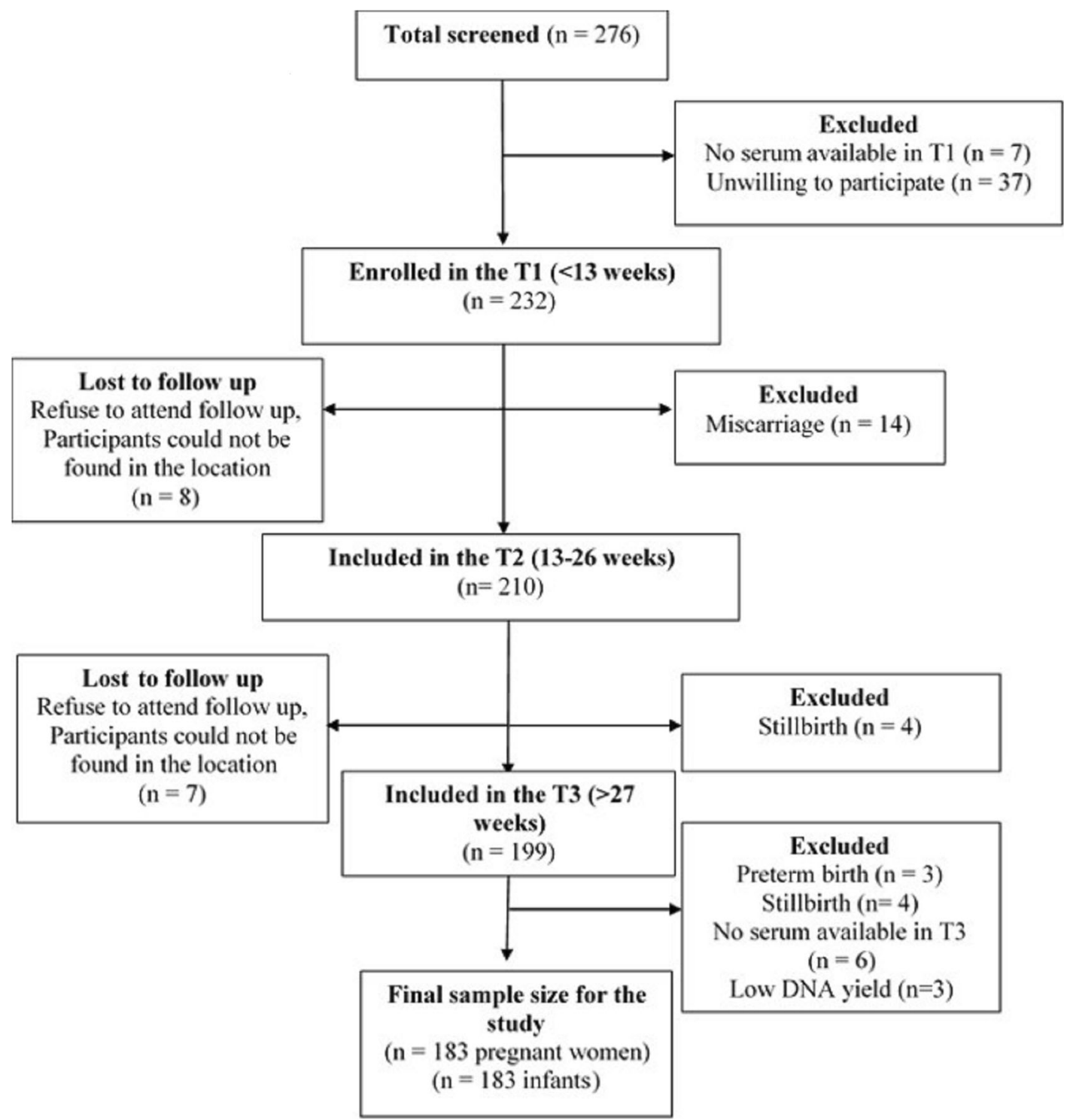

Fig. 1 Flowchart showing the selection of study participants. Pregnant women who were $<13$ weeks of gestation were recruited and followed up until the delivery to determine newborn anthropometry measurements. Out of 276 women, 90 were dropped out because of pregnancy loss, change of residence, not willing to continue research, and those who could not be contacted again. Out of 186 pregnant women who completed all requirements and attended follow-ups from the $\mathrm{T} 1$ to delivery, three individuals were excluded due to low DNA yield and hence a total of 183 mother and infant pairs were used for analysis. T1: first trimester; $\mathrm{T} 2$ : second trimester; $\mathrm{T} 3$ : third trimester 


\section{Anthropometric measurements}

Maternal anthropometric measurements (height, weight, and MUAC) were determined at enrolment and followed up during pregnancy. Pre-pregnancy BMI was calculated based on the height routinely measured at the clinic visit and prepregnancy body weight obtained at interview through maternal and child monitoring book. Maternal body weight was measured to the nearest $100 \mathrm{~g}$ using an electronic scale (Seca 815, Seca GmbH. Co. kg, Germany) and height was measured to the nearest millimeter using a stadiometer (Seca 217, Seca GmbH. Co. kg, Germany). The BMI calculation was based on the body weight $(\mathrm{kg})$ divided by the square of body height (m). Pre-pregnancy BMI was classified according to World Health Organization guidelines for Asian populations (underweight, $<18.5 \mathrm{~kg} / \mathrm{m}^{2}$; normal, $18.5-23.49 \mathrm{~kg} / \mathrm{m}^{2}$; overweight, 23.5-24.99 kg/m²; Pre-obese, 25-29.99 kg/m²; Obese, $\geq 30 \mathrm{~kg} / \mathrm{m}^{2}$ ) [18].

\section{Measuring serum 25-hydroxyvitamin D levels}

Maternal blood was collected two times under non-fasting conditions at $<13$ and $>27$ weeks of gestation. Serum samples were stored at $-70{ }^{\circ} \mathrm{C}$ until they were analyzed for $25(\mathrm{OH}) \mathrm{D}$ concentrations. Serum levels of $25(\mathrm{OH}) \mathrm{D}$ were assessed using Enzyme-linked immunosorbent assay (ELISA) from Diagnostic Biochemistry Canada (DBC) 25-Hydroxyvitamin D ELISA kit (DBC, London, Ontario Canada) and measured using xMark Microplate Spectrophotometer (Bio-Rad Laboratories Inc., Hercules, California, USA). The assay had a sensitivity of $5.5 \mathrm{ng} / \mathrm{mL}$ and an intra and inter-assay coefficient of variation of $5 \%$ and $8.1 \%$, respectively. The vitamin $\mathrm{D}$ status was defined as serum $25(\mathrm{OH}) \mathrm{D}<12 \mathrm{ng} / \mathrm{mL}$ (vitamin $\mathrm{D}$ deficient), $12-19 \mathrm{ng} / \mathrm{mL}$ (vitamin D insufficient), $\geq 20 \mathrm{ng} / \mathrm{mL}$ (vitamin D sufficient) according to Institute of Medicine (IOM) guidelines [19].

\section{SNP selection and genetic analysis}

We selected six candidate SNPs according to the following criteria: (1) biological importance in vitamin D synthesis, metabolism, transportation, or degradation; (2) SNPs with minor allele frequency of $>5 \%$, and (3) evidence of a significant association in previous GWASs. The selected genes were DHCR7 (rs12785878), CYP2R1 (rs12794714), GC (rs2282679), CYP24A1 (rs6013897), and VDR (rs2228570 and rs7975232) $[12,17,20]$ and the roles of these genes in the vitamin D cascade are shown in Supplementary Fig. 1.

Blood samples were collected from all the study participants. Genomic DNA was isolated from peripheral blood leukocytes using PureLink Genomic DNA Mini Kit (Invitrogen, Carlsbad, USA). The DNA concentration was determined using a NanoDrop spectrophotometer (Isogen Life Science,
De Meern, the Netherlands). Genotyping was performed at LGC Genomics, UK (http://www.lgcgroup.com/services/ genotyping). Genotype frequencies were tested against the Hardy-Weinberg equilibrium (HWE) using the $\chi^{2}$ test. Genotype frequencies of all SNPs were in Hardy Weinberg equilibrium and the minor-allele frequencies of the SNPs ranged from 0.18 to 0.39 (Supplementary Table 1).

\section{Pregnancy outcomes}

Gestational age at birth was calculated from estimated gestational age examined by obstetricians or midwives using transabdominal ultrasound performed or date of last menstrual period in the absence of ultrasound at the Maternal Clinic or Hospital. Infants' birth weight, birth length, and head circumference were recorded at birth using Seca mechanical measuring scales (Seca 803, Seca GmbH. Co. kg, Hamburg, Germany). We classified newborn anthropometry status according to World Health Organization Child Growth Standards for head circumference-for-age (small head circumference, $<35 \mathrm{~cm}$ and normal head circumference, $\geq 35 \mathrm{~cm}$ ), weight-for-age (low birth weight, $<2500 \mathrm{~g}$ and normal birth weight $\geq 2500 \mathrm{~g}$ ), and length-for-age (short birth length, $<50 \mathrm{~cm}$ and normal birth length, $\geq 50 \mathrm{~cm}$ ) [21].

\section{Sample size and power calculation}

The sample size was calculated for investigating the association between vitamin D levels and birth weight, which was the main objective of the VDPM study. Previous study found that $13.08 \mathrm{ng} / \mathrm{mL}$ difference of maternal vitamin $\mathrm{D}$ level between mothers of low birth weight neonate and those of normal birth weight neonate with standard deviation ranging from 18.50 to $20.16 \mathrm{ng} / \mathrm{mL}$ [22]. The sample size was calculated using the following formula [23].

$n=\frac{2(Z \alpha+Z \beta)^{2} S^{2}}{(U 1-U 2)^{2}}$

$\mathrm{n} \quad$ Sample size of each group.

$\mathrm{Z} \alpha \quad$ Value of standard normal distribution that is equal to $\alpha=0.05$ is 1.96 .

$\mathrm{Z} \beta \quad$ Value of standard normal distribution (90\%) that equal to $\beta=0.10$ is 1,28 .

S Outcome standard deviation based on the study by Khalessi et al. 2015 [23] is 18.5.

(U1- Difference of mean outcome in low birthweight and U2) normal birthweight status (13.08)

$n \quad 2(1,96+1,28) 2 \times 18.52 /(13.08) 2=41.96 \approx 42$.

Based on the above formula, the minimum number of samples required for each group is 42 to achieve a 
statistical power of $90 \%$ to test for the association between vitamin D levels and birth weight. Hence, we aimed to recruit a total sample size with minimum of 100 participants to account for a $20 \%$ drop-out. Given that there are no studies, to date, that have examined the association between genetic variants and vitamin D levels and adverse pregnancy outcomes in Indonesia, we were unable to calculate the power for the genetic analysis. Furthermore, genetic analysis was conducted as a retrospective post hoc analysis and hence the power calculation was not performed for the genetic study.

\section{Statistical analysis}

Data were analysed using the IBM SPSS Statistics for Windows (version 23.0; SPSS, Inc., Chicago, IL, USA). Continuous variables with normal distribution were presented as mean $\pm \mathrm{SD}$. Categorical variables were presented as frequency and percentage. The normality of distribution of outcome variables (maternal serum $25(\mathrm{OH}) \mathrm{D}$ levels) was tested by Kolmogorov-Smirnov test.

Bivariate Pearson correlation was established to examine the correlation of serum $25(\mathrm{OH}) \mathrm{D}$ levels in the first trimester with serum $25(\mathrm{OH}) \mathrm{D}$ levels in the third trimester. A multinomial logistic regression model was used to identify the association between vitamin D status during pregnancy and newborn anthropometry status such as birth weight status, head circumference status, and birth length status. A multivariate analysis using general linear model (GLM) was conducted to determine the association between vitamin D status and newborn anthropometry. Significant factors associated with vitamin D status were entered into the GLM to adjust for covariate variables such as age, pre-pregnancy BMI, gestational age birth, infant gender, and supplement intake during pregnancy.

Genetic risk score (GRS), which was the sum of risk alleles from the SNPs rs12785878 (DHCR7), rs12794714 (CYP2R1), rs2282679 (GC), rs6013897 (CYP24A1), and rs2228570 and rs7975232 (VDR) [12, 17, 20], was created. Furthermore, GRS was divided into three groups as "vitamin D-GRS", "synthesis-GRS" and "metabolismGRS". "Vitamin D-GRS" was obtained from all the six SNPs that play a role in the synthesis and metabolism of vitamin D. Two SNPs in genes encoding proteins involved in $25(\mathrm{OH}) \mathrm{D}$ synthesis (DHCR7 and CYP2R1) were included in the "synthesis-GRS" [12] and four SNPs in genes encoding proteins involved in $25(\mathrm{OH}) \mathrm{D}$ metabolism (GC, CYP24A1, VDR) were included in the "metabolism-GRS" [20].

The effect of GRSs on 25(OH)D levels and newborn anthropometry was assessed using univariate general linear models after adjustment for potential confounders (age, pre-pregnancy BMI, geography status, vitamin D and calcium supplement consumption during pregnancy and sunlight exposure status). The associations of GRSs with vitamin D status and newborn anthropometry (birth weight, birth length, head circumferences) were analysed using logistic regression analysis. The interaction between GRS and 25(OH)D levels during pregnancy (T1 and T3) on newborn anthropometry measurements was determined by including interaction terms [GRS*25(OH)D] in the model and adjusting for age, pre-pregnancy BMI, gestational age at birth, and infant's gender. The study objectives are shown in Fig. 2.

Correction for multiple testing was performed using Bonferroni correction. Corrected $P$ value for association analysis was $\leq 0.006$ [ $3 \mathrm{GRS} * 3$ maternal $25(\mathrm{OH}) \mathrm{D}$ level outcomes (T1, T3, and changes in $25(\mathrm{OH}) \mathrm{D}$ during pregnancy) $=9$ tests $]$. For the interaction analysis, corrected $\mathrm{P}$ value was $\leq 0.003$ [3 GRS * 2 maternal 25(OH)D outcomes (T1 and T3) * 3 newborn anthropometry outcomes (birth weight, birth length, and head (ircumference) $=18$ tests $]$.

\section{Results}

\section{Characteristic of the study population}

The characteristics of the study participants stratified based on maternal vitamin D status at T1 and T3 are shown in Table 1. There was a significant difference in diastolic blood pressure (DBP), and body weight during the third trimester and there was a significant difference in outdoor activity (hours/day) during the first trimester between those who were vitamin D deficient (VDD) and those with normal vitamin D status (NVD) $(p<0.05)$. In Table 1 , there was a significant difference in systolic blood pressure, bodyweight, and MUAC between T1 and T3 ( $<<0.05$, for all comparisons). Systolic blood pressure, bodyweight, and MUAC were significantly higher in T3 compared to T1. However, there was no significant difference in the levels of hemoglobin and diastolic blood pressure ( $p>0.05$, for all comparisons). The study participants were enrolled at an average age of $29.7 \pm 5.68$ years. The average of pre-pregnancy Body Mass Index (BMI) was $23.45 \pm 4.56 \mathrm{~kg} / \mathrm{m}^{2}$. The average gestational duration was $38.88 \pm 1.91$ weeks and $73.30 \%$ of deliveries were normal. Mean birth weight, birth length, and head circumference were $3204.87 \pm 494.99 \mathrm{~g}, 48.56 \pm 2.87 \mathrm{~cm}$, and $33.89 \pm 2.52 \mathrm{~cm}$, respectively. Approximately $6.80 \%(n=12)$ of newborn babies had low birth weight (LBW) status, while $5.40 \%$ $(n=10)$ were diagnosed with macrosomia. There were < $10 \%$ of cases who had adverse pregnancy outcomes such as LBW, SGA, and preterm birth (PTB). However, a higher number of women had babies with a small head circumference 


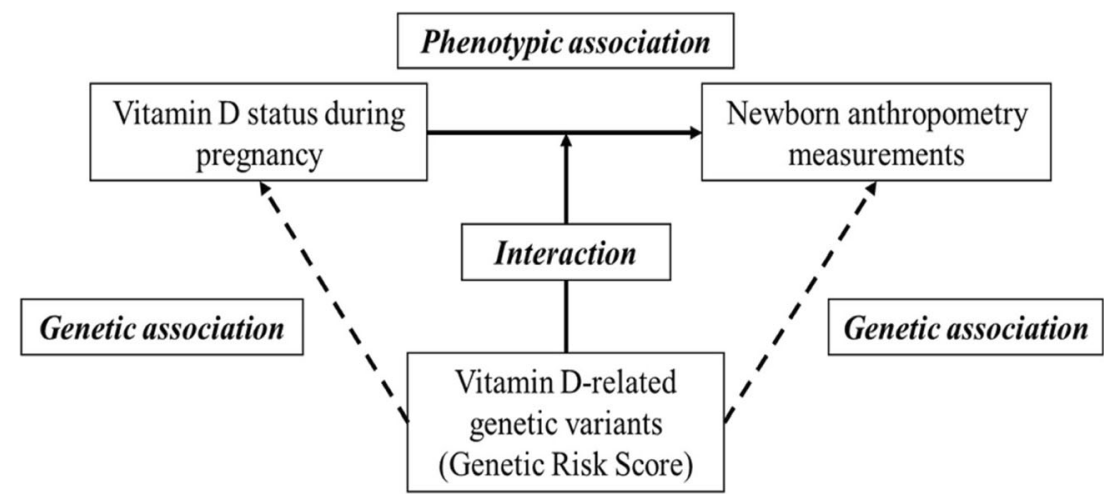

Fig. 2 Diagram representing the study objectives. Three possible associations and one possible interaction were examined. Broken lines represent genetic associations and unbroken lines represent phenotypic association and interaction between genetic risk score (GRS) and vitamin D status on newborn anthropometry measurements, respectively.

$(<35 \mathrm{~cm})$ and short birth length $(<50 \mathrm{~cm})(57.30 \%$ and $64.10 \%$, respectively).

Vitamin D status during pregnancy

Average maternal serum 25(OH)D level in T1 was $14.00 \pm$ $6.97 \mathrm{ng} / \mathrm{mL}$. Approximately $82.80 \%$ ( $n=154)$ of women were deficient $(47.30 \%, n=88)$ and insufficient $(35.50 \%, n=66)$ for vitamin $\mathrm{D}$. The serum $25(\mathrm{OH}) \mathrm{D}$ levels increased significantly during pregnancy $(P=0.0001, \mathrm{R}=0.425)$. In the $\mathrm{T} 3$, average maternal serum $25(\mathrm{OH}) \mathrm{D}$ level was $21.21 \pm 10.16 \mathrm{ng} /$ $\mathrm{mL}$. A total of $46.80 \%(n=87)$ of women were vitamin $\mathrm{D}$ sufficient, $34.40 \%(n=64)$ were insufficient and $18.80 \%$ $(n=35)$ were deficient. The prevalence of vitamin $\mathrm{D}$ deficiency and insufficiency in the T1 lowered from $82.80 \%(n=154)$ to $53.20 \%(n=99)$ in the T3.

\section{Association between maternal Vitamin D status during pregnancy and newborn anthropometry}

We found no significant association between 25(OH)D level during T1 and T3 and newborn anthropometric measurements ( $P>0.05$ for all comparisons). There was also no significant association between changes in vitamin $\mathrm{D}$ status during pregnancy and newborn anthropometry $(\mathrm{P}>0.05$ for all comparisons) (Table 2).

\section{Association between GRS and serum 25(OH)D levels during pregnancy}

There was a significant association between vitamin D-GRS and $25(\mathrm{OH}) \mathrm{D}$ levels in $\mathrm{T} 3(\mathrm{P}=0.004)$ and changes in $25(\mathrm{OH}) \mathrm{D}$ levels during pregnancy $(P=0.018)$, but not with T1 $25(\mathrm{OH}) \mathrm{D}$ levels $(P=0.157)$. The synthesis-GRS and metabolism-GRS had no effect on $25(\mathrm{OH}) \mathrm{D}$ levels and changes in $25(\mathrm{OH}) \mathrm{D}$ levels during pregnancy ( $P>0.05$ for all comparisons). The association between GRSs and serum 25(OH)D levels during pregnancy are shown in Table 3 and Fig. 3.
Phenotypic association between vitamin D status and newborn anthropometry measurements and the genetic associations between GRS and vitamin D status and newborn anthropometry measurements were investigated

\section{Association between GRSs and newborn anthropometry}

We observed no statistically significant association of the vitamin D-GRS, synthesis-GRS, and metabolism-GRS with newborn anthropometry measurements ( $P>0.05$ for all comparisons). Similar finding was observed even after classifying newborn anthropometry measurements into categorical variables $(\mathrm{P}>$ 0.05 for all comparisons) (Supplementary Tables 2 and 3).

\section{Interaction between GRS and 25(OH)D during pregnancy on newborn anthropometry}

None of the interactions were statistically significant except for the interaction between vitamin D-GRS and 25(OH)D concentrations in T3 on newborn head circumference measurement $(P=0.030)$. Further stratification of study participants based on head circumference cut-off points (small heads, $<35 \mathrm{~cm}$ and normal head, $\geq 35 \mathrm{~cm}$ ) [18] showed that mothers of neonates with head circumference $<35 \mathrm{~cm}$ had significantly lower $25(\mathrm{OH}) \mathrm{D}$ levels if they carried $\geq 4$ risk alleles compared to those who carried $\leq 3$ risk alleles (Fig. 4). However, after correction for multiple testing, this interaction was not considered statistically significant (Table 4).

\section{Association between SNPs and 25(OH)D during pregnancy}

Besides exploring the impact of GRS on 25(OH)D levels during pregnancy, the individual effect of the SNPs on $25(\mathrm{OH}) \mathrm{D}$ levels was also examined. Under a dominant genetic model, ApaI (rs7975232) SNP showed a significant association with 25(OH)D levels in both T1 (0.047) and T3 ( $p=0.043)$, where A allele carriers had significantly lower $25(\mathrm{OH}) \mathrm{D}$ concentrations. In addition, A allele carriers of the CYP2R 1 


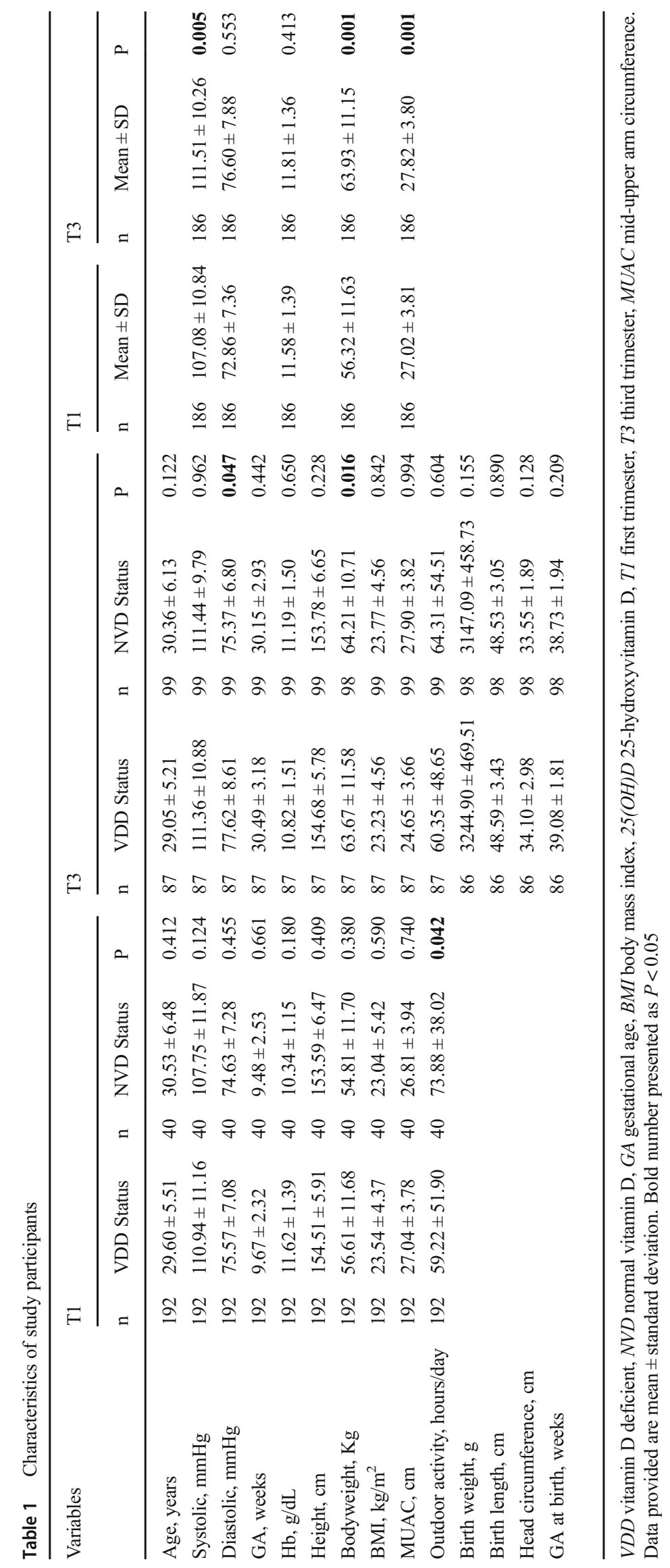


Table 2 Association between Vitamin D Status during Pregnancy and Newborn Anthropometry

\begin{tabular}{llll}
\hline Variables & \multicolumn{2}{l}{ Newborn Anthropometries } & \\
\cline { 2 - 4 } & Birth weight $(\mathrm{g})$ & Birth length $(\mathrm{g})$ & Head circumference $(\mathrm{cm})$ \\
\hline Sufficiency $(n=86)$ & $3147.09 \pm 458.73$ & $48.53 \pm 2.87$ & $33.55 \pm 1.89$ \\
Insufficiency $(n=63)$ & $3246.03 \pm 403.14$ & $48.86 \pm 1.89$ & $34.21 \pm 1.98$ \\
Defficiency $(\mathrm{n}=35)$ & $3242.86 \pm 576.65$ & $48.11 \pm 5.17$ & $33.91 \pm 4.25$ \\
P value & 0.301 & 0.618 & 0.386 \\
\hline
\end{tabular}

Vitamin D status during pregnancy defined based on Institute of Medicine (IOM): sufficient ( $\geq 20 \mathrm{ng} / \mathrm{mL}$ ), insufficient (12-19.99 $\mathrm{ng} / \mathrm{mL})$, and deficient $(<12 \mathrm{ng} / \mathrm{mL})$ [17]

$P$ values were adjusted for age, pre-pregnancy BMI, preterm status, vitamin D intake, sun exposure status and consumption of vitamin D and calcium supplements (rs12794714) SNP had significantly lower levels of 25(OH)D in both T1 $(p=0.001)$ and T3 (p $<=0.0001)$. There was also a significant association between $G C$ (rs22282679) SNP and $25(\mathrm{OH}) \mathrm{D}$ concentrations in $\mathrm{T} 3$ and changes in $25(\mathrm{OH}) \mathrm{D}$ levels during pregnancy $(P<0.001)$, but not in T1 $(P=081)$. None of the other associations were statistically significant (Supplementary Table 4).

\section{Discussion}

To our knowledge, this is the first study of its kind to investigate whether maternal vitamin $\mathrm{D}$ status was associated with newborn anthropometry measurements using a genetic approach. Our study demonstrated a high prevalence $(82.80 \%)$ of vitamin D deficiency among Indonesian pregnant mothers. Women who had $\geq 4$ vitamin D-decreasing risk alleles had significantly lower levels of serum $25(\mathrm{OH}) \mathrm{D}$ during pregnancy. Even though there was no direct association between GRS and newborn anthropometric measurements, mothers of neonates with head circumference $<35 \mathrm{~cm}$ had significantly lower $25(\mathrm{OH}) \mathrm{D}$ levels if they carried $\geq 4$ risk alleles suggesting that vitamin $\mathrm{D}$ deficiency during pregnancy can increase the genetic risk of adverse newborn anthropometry outcomes. Considering that more than half of the study participants were vitamin D deficient (83\%), establishing a vitamin D prevention program for pregnant women may be considered to maintain optimal foetal growth and development. Our findings, if replicated in future studies, may have a significant public health impact on initiating strategy to raise the awareness on the importance of vitamin D during pregnancy to prevent vitamin D deficiency and its adverse pregnancy outcomes.

Recent studies have shown a significant phenotypic association between serum 25(OH)D levels during pregnancy and adverse pregnancy outcomes such as gestational diabetes mellitus, pre-eclampsia, SGA, LBW and PTB [22, 24-26]. Evidence from observational studies have suggested that lower maternal $25(\mathrm{OH})$ D concentrations are associated with LBW

Table 3 Association pregnancy

\begin{tabular}{|c|c|c|c|c|c|c|}
\hline \multirow[t]{2}{*}{ Variables } & \multicolumn{2}{|c|}{ 25(OH)D T1 (ng/mL) } & \multicolumn{2}{|c|}{ 25(OH)D T3 (ng/mL) } & \multicolumn{2}{|c|}{ Changes $25(\mathrm{OH}) \mathrm{D}(\mathrm{ng} / \mathrm{mL})$} \\
\hline & Mean \pm SD & $\mathrm{P}$ & Mean \pm SD & $\mathrm{P}$ & Mean $\pm \mathrm{SD}$ & $\mathrm{P}$ \\
\hline \multicolumn{7}{|l|}{ Vitamin D-GRS total score* } \\
\hline less than or equal $3(n=99)$ & $14.77 \pm 8.22$ & 0.157 & $23.35 \pm 10.65$ & 0.004 & $8.58 \pm 9.54$ & 0.018 \\
\hline greater than or equal $4(n=85)$ & $12.98 \pm 5.40$ & & $18.74 \pm 8.95$ & & $5.76 \pm 9.50$ & \\
\hline \multicolumn{7}{|l|}{ Synthesis GRS score** } \\
\hline less than $2(n=137)$ & $14.37 \pm 7.65$ & 0.182 & $21.80 \pm 10.46$ & 0.287 & $7.43 \pm 9.64$ & 0.724 \\
\hline greater than or equal $2(n=46)$ & $12.72 \pm 5.03$ & & $19.65 \pm 9.06$ & & $6.93 \pm 9.62$ & \\
\hline \multicolumn{7}{|l|}{ Metabolism GRS score*** } \\
\hline less than or equal $3(n=147)$ & $14.07 \pm 7.55$ & 0.655 & $21.63 \pm 10.45$ & 0.482 & $6.57 \pm 9.53$ & 0.643 \\
\hline greater than or equal $4(n=37)$ & $13.44 \pm 4.96$ & & $19.56 \pm 8.73$ & & $6.11 \pm 9.90$ & \\
\hline
\end{tabular}

Bold number indicate $P<0.05 ; 25(\mathrm{OH}) \mathrm{D}, 25$-Hydroxyvitamin D levels; T1, First trimester; T3, Third trimester

$P$ values were adjusted for age, BMI, vitamin D supplements, sun exposure status, and geographical status

*All six SNPs in genes involved in the synthesis and metabolism of vitamin D

**Two SNPs in genes encoding proteins involved in 25(OH)D synthesis (DHCR7 and CYP2Rl) included in the "Synthesis score"

***Four SNPs in genes encoding proteins involved in 25(OH)D metabolism (GC, CYP24A1, VDR) are included in the "Metabolism score" 


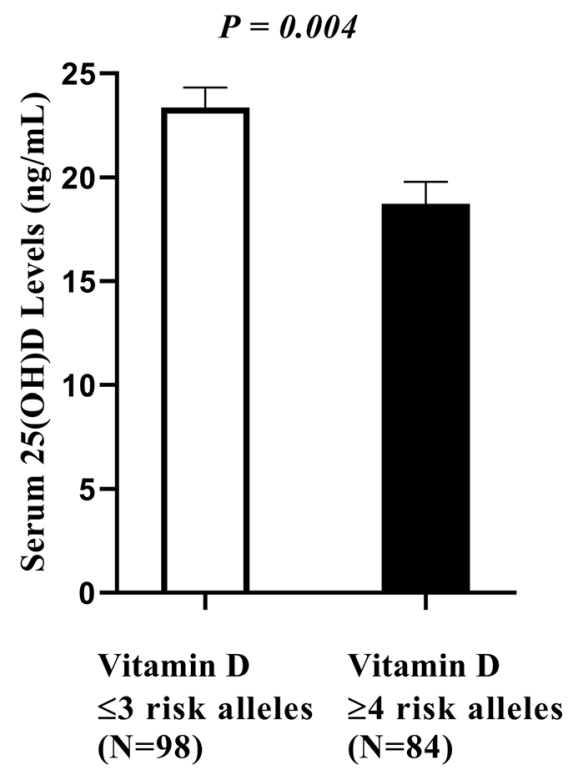

Fig. 3 Association between vitamin D-GRS and serum 25(OH)D levels in T3. Among those who carried $\geq 4$ risk alleles had lower serum $25(\mathrm{OH}) \mathrm{D}$ levels in T3 compared to women with $\leq 3$ risk alleles $(P=0.004)$

[7, 27, 28]. A recent prospective cohort study in 3658 Chinese mother-and-singleton-offspring pairs demonstrated that vitamin D deficiency during pregnancy was associated with neonatal birth size and estimated to double the risk of LBW [28]. In addition, two other studies that examined serum $25(\mathrm{OH}) \mathrm{D}$ levels during pregnancy found no association between first trimester vitamin D status and neonatal length but found a significant association in the third trimester [29, 30]. However, a few studies failed to show an association between maternal 25(OH)D levels and adverse pregnancy outcomes [29, 31-33]. These inconsistencies in findings could be due to confounding by unknown factors and the differences in cutpoints of vitamin D status used, sample size, population characteristics, skin pigmentation, exposure to sunlight, vitamin D supplementation and methods to measure $25(\mathrm{OH}) \mathrm{D}$ [24-26, 29, 31-35]. Given these limitations, we used a genetic approach, which is less prone to confounding, to explore the association between serum $25(\mathrm{OH}) \mathrm{D}$ levels during pregnancy and adverse pregnancy outcomes.

One of the main findings of our study was the significant association between GRS ( $\geq 4$ risk alleles) and lower serum $25(\mathrm{OH}) \mathrm{D}$ levels in the third trimester $(P=0.004)$ and changes in serum $25(\mathrm{OH}) \mathrm{D}$ levels during pregnancy. Our finding was similar to a study in 759 Chinese Han pregnant women from Zhoushan Pregnant Women Cohort (ZPWC) which also showed that individuals with $>3$ risk alleles had significantly lower 25(OH)D levels compared to those with 1 risk allele [36]. These findings are suggestive of the fact that the vitamin Drelated genetic variants might have additive or synergistic effects in influencing 25(OH)D concentrations in pregnant mothers.

Very few studies have assessed the association of vitamin D-related genotypes with 25(OH)D and newborn anthropometry (birth weight, birth length, head circumferences). A few recent studies have shown that $V D R$ gene variants influence birth weight and risk for SGA in black and white women [7, 27]. A recent Mendelian randomization study has also shown that polymorphisms in vitamin D-related genes, CYP $2 R 1$ [rs10741657] and DHCR7 [rs12785878], were associated with LBW suggesting a causal link between maternal vitamin D deficiency and neonatal birth weight [37]. Conversely, our study found no association between GRS and newborn anthropometry measurements (birth weight, birth length, head circumferences); however, mothers of neonates with small head circumference group $(<35 \mathrm{~cm})$ had significantly lower $25(\mathrm{OH}) \mathrm{D}$ levels if they carried $\geq 4$ risk alleles suggesting that vitamin $\mathrm{D}$ deficiency could increase the genetic risk of adverse neonatal outcomes. Our finding is in line with a previous
Fig. 4 Interaction between vitamin D-GRS and 25(OH)D levels in $\mathrm{T} 3(\mathrm{ng} / \mathrm{mL})$ on Head circumference. Mothers of neonates with head circumference $<35 \mathrm{~cm}$ had significantly lower $25(\mathrm{OH}) \mathrm{D}$ levels if they carried $\geq 4$ risk alleles compared to those who carried $\leq 3$ risk alleles $(P=0.040)$

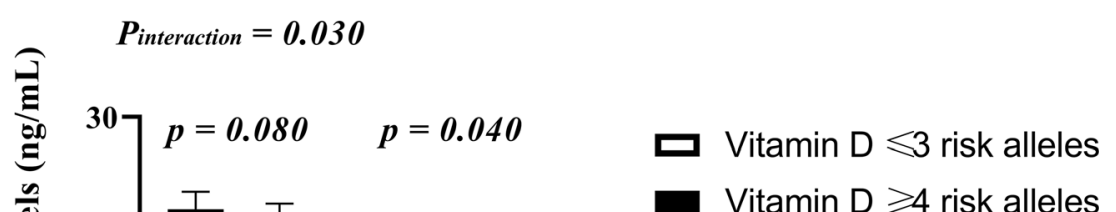


Table 4 Interaction between GRS and 25(OH)D on Newborn Anthropometry

Interaction between the GRS and 25(OH)D T1 on newborn anthropometry measurements

Interaction between vitamin D-GRS $25(\mathrm{OH}) \mathrm{D}$ T1 on birth weight Interaction between vitamin D-GRS*25(OH)D T1 on birth length

$2.72 \pm 10.55$

(0.797)

Interaction between synthesis-GRS $* 25(\mathrm{OH}) \mathrm{D}$

$\mathrm{T} 1 \mathrm{on}$ birth weight

$-0.23 \pm 14.19$

(0.472)

Interaction between metabolism-GRS*25(OH)D

$\mathrm{T} 1$ on birth weight

$-5.31 \pm 15.85$

(0.738)

Interaction between the GRS and 25(OH)D T3 on newborn anthropometry measurements

Interaction between vitamin D-GRS*25(OH)D

T3 on birth weight

$9.56 \pm 6.80$

(0.162)

Interaction between synthesis-GRS*25(OH)D

T3 on birth weight

$7.39 \pm 8.14$

(0.366)

Interaction between metabolism-GRS*25(OH)D

$\mathrm{T} 3$ on birth weight

$5.99 \pm 9.16$

(0.514)
$0.04 \pm 0.06$

$(0.510)$

Interaction between synthesis-GRS $* 25(\mathrm{OH}) \mathrm{D}$

T1 on birth length

$-0.11 \pm 0.08$

(0.897)

Interaction between metabolism-GRS*25(OH)D

$\mathrm{T} 1$ on birth length

$0.121 \pm 0.10$

(0.214)

Interaction between vitamin D-GRS $* 25(\mathrm{OH}) \mathrm{D}$

T3 on birth length

$0.06 \pm 0.04$

(0.199)

Interaction between synthesis-GRS $* 25(\mathrm{OH}) \mathrm{D}$

$\mathrm{T} 3$ on birth length

$0.04 \pm 0.05$

(0.426)

Interaction between metabolism-GRS*25(OH)D

$\mathrm{T} 3$ on birth length

$0.04 \pm 0.056$

$(0.475)$
Interaction between vitamin D-GRS*25(OH)D

$\mathrm{T} 1 \mathrm{on}$ head circumference

$0.09 \pm 0.05$

(0.098)

Interaction between synthesis-GRS $* 25(\mathrm{OH}) \mathrm{D}$

$\mathrm{T} 1$ on head circumference

$0.07 \pm 0.07$

(0.312)

Interaction between metabolism-GRS*25(OH)D

$\mathrm{T} 1$ on head circumference

$0.02 \pm 0.08$

(0.799)

Interaction between vitamin D-GRS*25(OH)D

T3 on head circumference

$0.08 \pm 0.03$

(0.031)

Interaction between synthesis-GRS $* 25(\mathrm{OH}) \mathrm{D}$

$\mathrm{T} 3$ on head circumference

$0.08 \pm 0.04$

$(0.075)$

Interaction between metabolism-GRS*25(OH)D

$\mathrm{T} 3$ on head circumference

$0.08 \pm 0.05$

$(0.105)$

$T 1$ first trimester, $T 3$ third trimester, 25(OH)D 25-hydroxyvitamin D

Values are beta coefficients \pm standard errors. $\mathrm{P}$ values are provided within brackets

$P$ values were adjusted for age, pre-pregnancy BMI, supplement consumption, gestational age at birth, and gender of the infants

study which had also shown that mothers of neonates with small head circumference $(<35 \mathrm{~cm})$ had significantly lower levels of 25(OH)D [22]; but the previous study did not explore the genetic susceptibility of the pregnant mothers. Future studies investigating the genetic basis of the associations between vitamin D status during pregnancy and newborn anthropometry measurements are required to confirm or refute our findings.

While most of the genetic variants chosen for our study have not been studied previously in relation to the risk of adverse pregnancy outcomes, VDR gene variants (rs2228570 and rs7975232) have been shown to be associated with the risk of adverse pregnancy outcomes such as PTB, LBW, and SGA status [27, 38-42]. However, there are also a few studies which failed to provide evidence for the relationship between rs7975232 (VDR) and PTB risk [38, 39]. We were unable to explore the association between $V D R$ variants and PTB risk in the present study as the PTB variable was not available for all study participants; however, we examined other newborn anthropometry measurements such as birth weight, birth length and head circumference. $V D R$ is required for the vitamin D metabolic pathway where its activation regulates the expression of genes involved in cell proliferation and differentiation [43]. Studies have shown the expression of $V D R$ in placental tissues suggesting the role of vitamin D in reproduction and maternal to foetal nutrient transfer mechanism [44, 45].
Hence, the beneficial effects of vitamin D on foetal transfer mechanism can be affected by the decrease in VDR expression. Furthermore, it is possible that $V D R$ might be a key factor in maternal to foetal nutrient transfer mechanism and adverse pregnancy outcomes and therefore serves as a strong candidate gene for our study.

The current study has some limitations. Firstly, the sample size was relatively modest; however, we were still able to identify significant associations and interactions in 183 mother and infant pairs after correction for multiple testing. Secondly, sunlight exposure variable was a self-reported outdoor activity and hence the bias involved in assessing sun exposure status cannot be ruled out. Thirdly, we have controlled for known major confounders, but we cannot completely exclude the possibility of other confounders such as the impact of vitamin D-fortified foods as this information was not collected in the present study. Compared to previous studies [1-3, 28], our study has several strengths. Firstly, the prospective cohort study analysis may reveal stable results and allows the examination of gestation-specific associations of maternal vitamin D status and newborn anthropometry. Secondly, measurements of $25(\mathrm{OH}) \mathrm{D}$ levels in different trimesters provides more information about the association between SNPs and vitamin D status during pregnancy. Fourthly, data were collected in the same season (dry season) and hence our study findings are unlikely to be affected by seasonal 
variation Thirdly, study participants were enrolled from single ethnicity (Indonesian Minangkabau women), which avoids genetic heterogeneity. Lastly, this is the first study of its kind in Indonesian pregnant mothers exploring the association of maternal vitamin D status and newborn anthropometry using a genetic approach which is less prone to confounding. Future research should focus on conducting large prospective studies, Mendelian Randomization studies and clinical trials to establish the causal effect of vitamin D deficiency on adverse pregnancy outcomes.

\section{Conclusion}

In conclusion, we provide an evidence for an impact of vitamin D-related genetic variations on newborn anthropometry measurements through the influence of serum $25(\mathrm{OH}) \mathrm{D}$ levels among Indonesian pregnant Minangkabau women. Before initiating strategies for the implementation of vitamin D supplementation programs in Indonesia to prevent adverse pregnancy outcomes, further large studies are required to confirm our findings.

Acknowledgments The authors would like to acknowledge the participation of the volunteers, nutrition students, research assistants, biomedical laboratory assistant, and field data enumerator for their support in this study. We appreciate all the subjects for their co-operation and support of this study. Special thanks are also due to all the midwives at the maternal clinics in Payakumbuh, Padang, Lima Puluh Kota, Pariaman, and Padang Pariaman. ASA acknowledges the support from the Ministry of Research, Technology and Higher Education (Menristekdikti) of Indonesia for the Peningkatan Kualitas Publikasi Internasional (PKPI) scholarship program in collaboration with the Department of Food and Nutritional Sciences, University of Reading, UK.

Availability of data and material Data from this project will not be shared because additional results from the study are yet to be published.

Author contributions ASA carried out data collection and statistical analysis; RR carried out power and sample size calculation; ASA and KSV interpreted the data and drafted the manuscript; KSV, NIL, YY and SGM conceived, designed and supervised the study; JAL, BEA, NIL, YY and SGM helped revise the manuscript; EE assisted with data collection, monitoring and evaluation of participants, and project administration. All authors read and approved the final manuscript.

Funding This research was funded by Directorate General of Higher Education Ministry of National Education (KEMENRISTEK DIKTI), Indonesia, with project name The Research of Master Program Leading to Doctoral Degree for Excellent Students (PMDSU Batch-2) in the year of 2018 (Grant No: 050/SP2HL/LT/DRPM/2018) and Indonesian Danone Institute Foundation (Grant No: 007/ROG-D/IDIF/X2016). The views expressed herein are those of the individual authors and do not necessarily reflect those of Indonesian Danone Institute Foundation (IDIF).

\section{Compliance with ethical standards}

Conflict of interest The authors declare that they have no competing interests.
Ethics approval and consent participate This study was conducted in accordance with the declaration of Helsinki and approved by the Ethics Committees of Medical Faculty, Andalas University (No. 262/KEP/FK/ 2016). All women provided written informed consent prior to the start of the data collection.

\section{Consent for publication Not applicable.}

Open Access This article is licensed under a Creative Commons Attribution 4.0 International License, which permits use, sharing, adaptation, distribution and reproduction in any medium or format, as long as you give appropriate credit to the original author(s) and the source, provide a link to the Creative Commons licence, and indicate if changes were made. The images or other third party material in this article are included in the article's Creative Commons licence, unless indicated otherwise in a credit line to the material. If material is not included in the article's Creative Commons licence and your intended use is not permitted by statutory regulation or exceeds the permitted use, you will need to obtain permission directly from the copyright holder. To view a copy of this licence, visit http://creativecommons.org/licenses/by/4.0/.

\section{References}

1. Wibowo N, Bardosono S, Irwinda R, Syafitri I, Putri AS, Prameswari N. Assessment of the nutrient intake and micronutrient status in the first trimester of pregnant women in Jakarta. Med J Indones. 2017;26(2):109-15.

2. Bardosono S. Maternal micronutrient deficiency during the first trimester among Indonesian pregnant women living in Jakarta. JKI. 2016;4(2):76-81.

3. Aji AS, Desmawati D, Yerizel E, Lipoeto NI. The association between lifestyle and maternal vitamin D levels during pregnancy in West Sumatra, Indonesia. Asia Pac J Clin Nutr. 2018;27(6):1286-93.

4. Lipoeto N, Aji A, Faradila F, Ayudia F, Sukma N. Maternal vitamin D intake and serum 25-hydroxyvitamin D (25(OH)D) levels associated with blood pressure: a cross-sectional study in Padang, West Sumatra. MJN. 2018;24(3):407-15.

5. Aji AS, Erwinda E, Yusrawati Y, Malik SG, Lipoeto NI. Vitamin D deficiency status and its related risk factors during early pregnancy: a cross-sectional study of pregnant Minangkabau women, Indonesia. BMC Pregnancy Childb. 2019;19(1):183.

6. Wagner CL, Taylor SN, Johnson DD, Hollis BW. The role of vitamin D in pregnancy and lactation: emerging concepts. Women's Health (Lond Engl). 2012;8(3):323-40.

7. Holick MF. High prevalence of vitamin D inadequacy and implications for health. Mayo Clin Proc. 2006;81(3):353-73.

8. Bodnar LM, Catov JM, Zmuda JM, Cooper ME, Parrott MS, Roberts JM, et al. Maternal serum 25-Hydroxyvitamin D concentrations are associated with small-for-gestational age births in white women. J Nutr. 2010;140(5):999-1006.

9. Warrington R, Watson W, Kim HL, Antonetti FR. An introduction to immunology and immunopathology. Allergy Asthma Clin Immunol. 2011;7 Suppl 1:S1.

10. Christian P, Stewart CP. Maternal micronutrient deficiency, fetal development, and the risk of chronic disease. J Nutr. 2010;140(3): 437-45.

11. Zosky GR, Hart PH, Whitehouse AJO, Kusel MM, Ang W, Foong $\mathrm{RE}$, et al. Vitamin D deficiency at 16 to 20 weeks' gestation is associated with impaired lung function and asthma at 6 years of age. Ann Am Thorac Soc. 2014;11(4):571-7.

12. Guoying W, Xin L, Tami RB, Colleen P, Tina LC, Xiaobin W. Vitamin D trajectories from birth to early childhood and elevated 
systolic blood pressure during childhood and adolescence. Hypertension. 2019;74(2):421-30.

13. Shea M, Benjamin E, Dupuis J, Massaro J, Jacques P, D’Agostino $\mathrm{R}$, et al. Genetic and non-genetic correlates of vitamins $\mathrm{K}$ and $\mathrm{D}$. Eur J Clin Nutr. 2009;63(4):458-64.

14. Wang TJ. Common genetic determinants of vitamin D insufficiency: a genome-wide association study. Lancet. 2010;376(9736):180-8.

15. Sulem P, Gudbjartsson DF, Stacey SN, Helgason A, Rafnar T, Magnusson KP, et al. Genetic determinants of hair, eye and skin pigmentation in Europeans. Nat Genet. 2007;39(12):1443-52.

16. Han J, Kraft P, Nan H, Guo Q, Chen C, Qureshi A, et al. A genomewide association study identifies novel alleles associated with hair color and skin pigmentation. PLoS Genet. 2008;4(5):e1000074.

17. Nan H, Kraft P, Qureshi AA, Guo Q, Chen C, Hankinson SE, et al. Genome-wide association study of tanning phenotype in a population of European ancestry. J Invest Dermatol. 2009;129(9):2250-7.

18. Sakaki T, Kagawa N, Yamamoto K, Inouye K. Metabolism of vitamin D3 by cytochromes P450. Front Biosci. 2005;10:119-34.

19. Ahn J, Yu K, Stolzenberg-Solomon R, Simon KC, McCullough ML, Gallicchio L, et al. Genome-wide association study of circulating vitamin D levels. Hum Mol Genet. 2010;19(13):2739-45.

20. WHO. Appropriate body-mass index for Asian populations and its implications for policy and intervention strategies. Lancet. 2004;363(9403):157-63.

21. Holick MF, Vitamin D. Deficiency. N Engl J Med. 2007;357(3):266-81.

22. Berry DJ, Vimaleswaran KS, Whittaker JC, Hingorani AD, Hyppönen E. Evaluation of genetic markers as instruments for Mendelian randomization studies on vitamin D. PLoS One. 2012;7(5):e37465.

23. World Health Organization, World Health Organization Nutrition for Health and Development. WHO Child Growth Standards: Head Circumference-for-age, Arm Circumference-for-age, Triceps Skinfold-for-age and Subscapular Skinfold-for-age : Methods and Development. World Health Organization; 2007. 238 p.

24. Khalessi N, Kalani M, Araghi M, Farahani Z. The relationship between maternal Vitamin D deficiency and low birth weight neonates. J Family Reprod Health. 2015;9(3):113-7.

25. Lemeshow S, Hosmer DW, Klar J, Lwanga SK. Adequacy of sample size in health studies. World Health Organization 1990;1-4.

26. Wei SQ. Vitamin D and pregnancy outcomes. Curr Opin Obstet Gynecol. 2014;26(6):438-47.

27. Toko EN, Sumba OP, Daud II, Ogolla S, Majiwa M, Krisher JT, et al. Maternal Vitamin D status and adverse birth outcomes in children from rural Western Kenya. Nutrients. 2016;7:8(12).

28. Hanieh S, Ha TT, Simpson JA, Thuy TT, Khuong NC, Thoang DD, et al. Maternal Vitamin D status and infant outcomes in rural Vietnam: a prospective cohort study. PLoS One. 2014;9(6):e99005.

29. Swamy GK, Garrett ME, Miranda ML, Ashley-Koch AE. Maternal Vitamin D receptor genetic variation contributes to infant Birthweight among black mothers. Am J Med Genet A. 2011;155(6):1264-71.

30. Chen Y-H, Fu L, Hao J-H, Yu Z, Zhu P, Wang H, et al. Maternal Vitamin D deficiency during pregnancy elevates the risks of small for gestational age and low birth weight infants in Chinese population. J Clin Endocrinol Metab. 2015;100(5):1912-9.

31. Morley R, Carlin JB, Pasco JA, Wark JD, Ponsonby A-L. Maternal 25hydroxyvitamin D concentration and offspring birth size: effect modification by infant VDR genotype. Eur J Clin Nutr. 2009;63(6):802-4.
32. Francis EC, Hinkle SN, Song Y, Rawal S, Donnelly SR, Zhu Y, et al. Longitudinal maternal Vitamin D status during pregnancy is associated with neonatal anthropometric measures. Nutrients. 2018;2:10(11).

33. Bhupornvivat N, Phupong V. Serum 25-hydroxyvitamin D in pregnant women during preterm labor. Asia Pac J Clin Nutr. 2017;26(2): 287-90.

34. Harvey NC, Holroyd C, Ntani G, Javaid K, Cooper P, Moon R, et al. Vitamin $\mathrm{D}$ supplementation in pregnancy: a systematic review. Health Technol Assess. 2014;18(45):1-190.

35. Thiele DK, Erickson E, Snowden J. Pregnancy outcomes and vitamin D status in the Pacific Northwest. FASEB J. 2016;30(1 supplement): 1150.24 .

36. Schneuer FJ, Roberts CL, Guilbert C, Simpson JM, Algert CS, Khambalia AZ, et al. Effects of maternal serum 25hydroxyvitamin D concentrations in the first trimester on subsequent pregnancy outcomes in an Australian population. Am J Clin Nutr. 2014;99(2):287-95.

37. Chen Y, Zhu B, Wu X, Li S, Tao F. Association between maternal vitamin $\mathrm{D}$ deficiency and small for gestational age: evidence from a meta-analysis of prospective cohort studies. BMJ Open. 2017;7(8): e016404.

38. Shao B, Jiang S, Muyiduli X, Wang S, Mo M, Li M, et al. Vitamin D pathway gene polymorphisms influenced vitamin $D$ level among pregnant women. Clin Nutr. 2017;37(6):2230-7.

39. Tyrrell J, Richmond RC, Palmer TM, Feenstra B, Rangarajan J, Metrustry S, et al. Genetic evidence for causal relationships between maternal obesity-related traits and birth weight. JAMA. 2016;315(11):1129-40

40. Rosenfeld T, Salem H, Altarescu G, Grisaru-Granovsky S, Tevet A, Birk R. Maternal-fetal vitamin D receptor polymorphisms significantly associated with preterm birth. Arch Gynecol Obstet. 2017;296(2):215-22.

41. Baczyńska-Strzecha M, Kalinka J. Influence of Apa1 (rs7975232), Taq1 (rs731236) and Bsm1 (rs154410) polymorphisms of vitamin D receptor on preterm birth risk in the polish population. Ginekol Pol. 2016;87(11):763-8.

42. Workalemahu T, Badon SE, Dishi-Galitzky M, Qiu C, Williams MA, Sorensen T, et al. Placental genetic variations in vitamin D metabolism and birthweight. Placenta. 2017;50:78-83.

43. Manzon L, Altarescu G, Tevet A, Schimmel MS, Elstein D, Samueloff A, et al. Vitamin D receptor polymorphism FokI is associated with spontaneous idiopathic preterm birth in an Israeli population. Eur J Obstet Gynecol Reprod Biol. 2014;177:84-8.

44. Patel HV, Patel NH, Sodagar NR. Vitamin d receptor (VDR) gene polymorphism and maternal vitamin d deficiency in indian women with preterm birth (PTB). Asian J Pharm Clin Res. 2017;10(9): 219-23.

45. Murthi P, Yong HEJ, Ngyuen TPH, Ellery S, Singh H, Rahman R, et al. Role of the placental Vitamin D receptor in modulating Fetoplacental growth in fetal growth restriction and preeclampsiaaffected pregnancies. Front Physiol. 2016;7(43):1-7.

Publisher's note Springer Nature remains neutral with regard to jurisdictional claims in published maps and institutional affiliations. 


\section{Affiliations}

Arif Sabta Aji ${ }^{1,2} \cdot$ Erwinda Erwinda $^{3} \cdot$ Rosfita Rasyid $^{3}$ - Yusrawati Yusrawati ${ }^{4}$ Safarina G Malik ${ }^{5}$ Buthaina Alathari $^{6}$. Julie Anne Lovegrove ${ }^{6} \cdot$ Nur Indrawaty Lipoeto ${ }^{7} \cdot$ Karani Santhanakrishnan Vimaleswaran ${ }^{6}$

1 Department of Biomedical Science, Faculty of Medicine, Andalas University, Padang 25127, Indonesia

2 Department of Nutrition, Faculty of Health Sciences, Alma Ata University, Yogyakarta 55183, Indonesia

3 Department of Public Health, Faculty of Medicine, Andalas University, Padang, West Sumatra 25127, Indonesia
Department of Obstetrics and Gynecology, Faculty of Medicine, Andalas University, Padang 25127, Indonesia

5 Eijkman Institute for Molecular Biology, Jakarta 10430, Indonesia

6 Hugh Sinclair Unit of Human Nutrition, Department of Food and Nutritional Sciences, University of Reading, Reading, UK

7 Department of Nutrition, Faculty of Medicine, Andalas University, Padang 25127, Indonesia 